\title{
The Impact Of Decision-Making On Production Activities
}

Hiroki Inagaki, NTT Data Corporation, Japan

Daisuke Doyo, Aoyama Gakuin University, Japan

\begin{abstract}
This study used control theory to model sales planning, long-term planning, rolling planning, materials planning, short-term planning, manufacturing, delivery and sale, and investigated how factors required for decision-making in each planning phase impact the overall planning through simulations. To find the degree of impact each phase has on the overall plan, the investigation method involved used each factor of planning as a variable in the control model. And the differences in results between impacts, when simulated by individually making them into constants and when simulated as a variable, were calculated. The findings of this study are considered to contribute to enhance corporate competitiveness by enabling appropriate planning, production equipment and technologies for production activities which actually produce profit.
\end{abstract}

Keywords: Supply Chain Management, Control Theory, Production Planning

\section{INTRODUCTION}

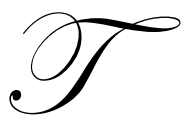

he basic decision-making of production activities in the manufacturing industry includes the determination of target profits, planning profits, planning cost, budget distribution, sales planning, production planning, materials planning and scheduling. The planning is conducted in a series starting with the establishment of a target profit, then on to sales planning and budget distribution based on planning profit and planning cost, and finally concluding with long-term planning, rolling planning and short-term planning (scheduling). The necessary elements for decision-making in each planning phase are already decided in upper-stream planning. For this reason, in order to realize a smooth decision from upstream to downstream planning, a swift exchange of information is required between each planning phase (Najafi, Bennett, 1984, Wiendahl, 2001, Ortega, Lin, 2004, Schwaninger, Vrhovec, 2006).

When making decisions in this flow, it is particularly important to accurately communicate the decision information made in the upstream phase to the downstream phase. In other words, when reflecting the elements of decision-making made upstream to the downstream planning, it is necessary to faithfully reflect the intentions of the upstream decision-making on the downstream decision-making. This is because the Bullwhip effect (Forrester,1958,1961) of information deterioration can occur, causing increased fluctuation in decision-making information while going from upstream to downstream. Therefore, it is necessary to nail down the accuracy of the factors required as decision-making items in each planning phase to improve the accuracy of the planning. Please note that the 'accuracy' mentioned in this study indicates the impact on inventory fluctuation. The higher the accuracy, the smaller the fluctuation in inventory would be.

Taking short-term planning as an example, it is considered possible to suppress information deterioration by deliberating on the accuracy of factors relating to the decision-making items, such as planned production volume, delivery date, line production capacity, current inventory of finished products, materials inventory, number of workers and inventory cost (Doyo et al., 2007). In other words, there is a possibility that there are factors that need close inspection and those that do not. When the degree of impact of factors that have an impact on the decision-making items are made clear, information deterioration can be easily inhibited.

The purpose of this study is to identify the degree of impact of factors required for each decision-making item in each planning phase by constructing a control model of a standard production activity. The factors required as decision-making items are integrated into the control model as variables that vary by their input values. This function allows for control of fluctuations in each inventory. Typically, as shown in Figure 1, higher accuracy is 
obtained by considering greater number of factors. The result obtained from the control model subsuming all factors is defined as the highest accuracy. When one out of those decision-making items is replaced as a constant and its impact neutralized, the result should be a lower accuracy compared to the highest accuracy. By comparing these two, the required accuracy for that factor is defined. This process is implemented on all factors and the difference between the average value and standard deviation of inventory obtained as a result is evaluated. The greater the difference, the greater the degree of impact that factor would be.

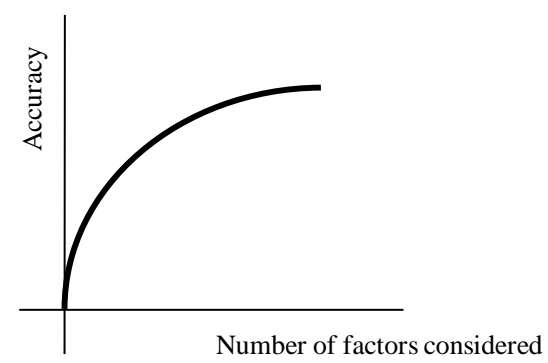

Figure 1: Graph of Number of Factors Considered and Overall Accuracy

\section{SUBJECT OF STUDY}

This study adopted a general model, which comprised of procurement, manufacturing, distribution and order-receiving functions, in addition to the planning phases of sales planning, long-term planning, rolling planning, materials planning and short-term planning.

As described in Figure 3, a simulation is conducted on a feedback model from sales planning to distribution and order-receiving. Figure 2 shows the overall feedback system, but the model is constructed in such a way that each planning phase has a feedback sub-system.

Demand is forecasted in sales planning. Using the result of the forecast, aggregate production planning, which is the long-term planning phase, is implemented. This is followed by the master production planning, which is a rolling planning phase, and from this result, the material requirements planning (MRP) as the materials planning phase and the scheduling as a short-term planning phase are made. Manufacturing and distribution are processed and orders are received according to the schedule. Using the proceeds of this term, the sales planning for the following term is made.

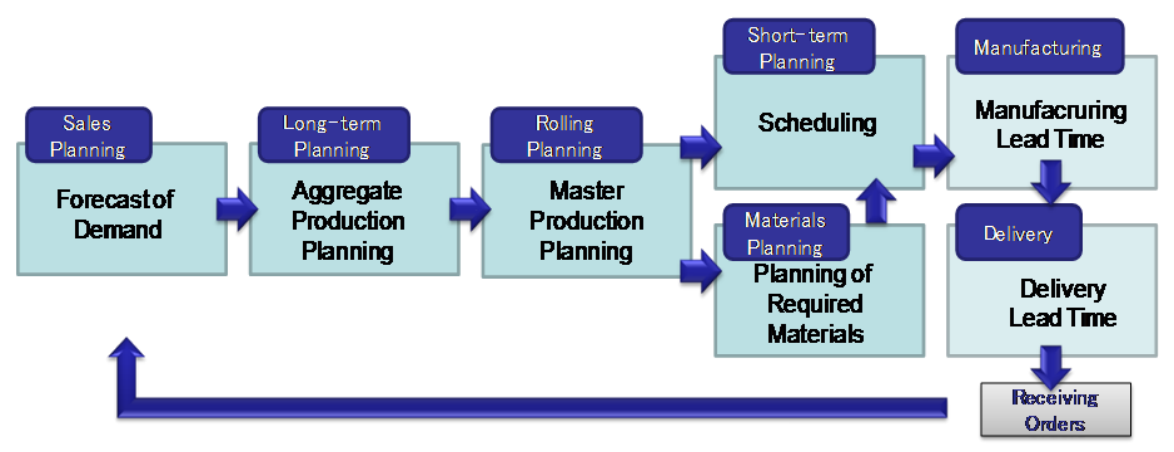

Figure 2: Overview of General Model 


\section{MODELING}

\subsection{Sales Planning}

Typically, methods such as the exponential smoothing method, time series analysis, moving average method, weighted moving average method and iterated moving average method are used in sales planning; this study employs the exponential smoothing method. The model in this study enables demand forecasting by the control of smoothing constant $\alpha$. The closer the smoothing constant $\alpha$ is to 1 , the more the focus is on the immediately preceding actual demand, and the closer it is to 0 , the more the focus centers on the progression of past forecasts. The average of past prediction error and the immediately preceding prediction error are compared, and whichever has less significant error is weighted. With the actual demand as $Y$ and the important forecasted value as $F$, the smoothing constant $\alpha$ for term $t$ can be defined by the following equation (1).

$$
\alpha=1-\left(\frac{1}{2}\right)^{\sum_{n} \frac{(t-1)(Y t-1-F t-1)}{Y n-F n}}
$$

\subsection{Long-Term Planning}

During long-term planning, a production planning based on the cut-and-try method of the aggregate production planning is conducted. To determine the planned volume of production, the cost with the smallest sum out of personnel unit cost, the inventory unit cost and the opportunity loss unit cost is chosen through the four types of approaches, which are the demand-tracking type, production-leveling/inventory-responsive type, production-leveling/underproduction type and production-leveling/balancing type. The personnel unit cost, the inventory unit cost and the opportunity loss unit cost are given as constants. The production volume is determined so that the sum of the total inventory cost and total opportunity loss cost is the lowest.

First, the cumulative planned production volume is defined by a linear function, as shown in the following equation (2) in relation to the cumulative predicted demand volume $f(u)$, as shown in Figure 3.

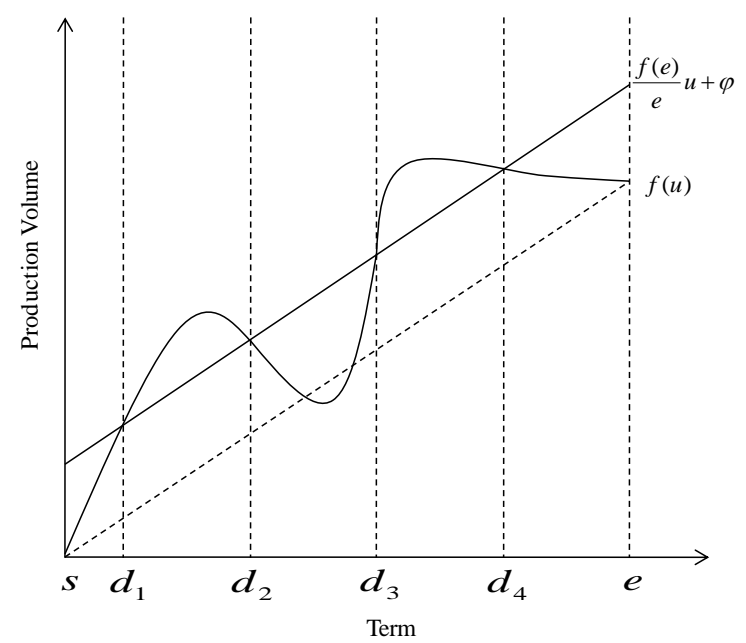

Figure 3: Concept of Planned Production Volume Control

$$
f(u)=\frac{f(e)}{e} u+\varphi
$$


$\varphi$ would be the intercept of the linear function. The intersecting points of the functions for the cumulative predicted demand volume and the cumulative planned production volume are specified as

$d_{1}, d_{2}, d_{3}, \ldots$, and these vertexes can be obtained from the value of $u$, which is the solution to the equation (2). Integration is then performed for each term and they are divided into inventory volume and opportunity loss volume.

$$
\begin{aligned}
& O_{n}=\int_{d_{n}}^{d_{n+1}} f(u)-\frac{f(e)}{e} u+\varphi d u \\
& S_{n}=\int_{d_{n}}^{d_{n+1}}\left|f(u)-\frac{f(e)}{e} u+\varphi\right| d u
\end{aligned}
$$

$O_{n}$ and $S_{n}$ are weighted according to whether it is for inventory cost or opportunity loss cost. Finding the solution for $\varphi$ using equation (5) gives the cumulative planned production volume line.

$$
C_{s} \sum O_{n}=C_{o} \sum S_{n}
$$

\subsection{Rolling Planning}

In the rolling planning phase, the master production scheduling is performed. The aggregate production plan (long-term plan) is broken down by item to identify the quantity of each item and the planned time of production discontinuation in a day unit to a week unit. This study assumed four product items as production items. The production volume for each item is determined based on past sales data. Given that the sales data for each product is $Y_{i}$ and the rate of production volume for each product in term $u$ is $\delta_{i}(t)$, then $\delta_{i}(t)$ is defined as equation (6) and the production quantity $P_{i}(u)$ for each item is as defined by equation (7).

$$
\begin{aligned}
& \delta_{i}(t)=\sum_{n} \frac{Y_{i n}}{Y_{n}} \\
& P_{i}(u)=\delta_{i}(u) A_{v}(u)
\end{aligned}
$$

The term of the plan is one month. Based on the long-term plan already decided at the beginning of the current term, the planned production volume is adjusted according to the present inventory. Therefore, not only is the total planned production volume decided in the long-term plan allocated to products so that it accurately meets the demand in the rolling planning, but it also becomes critical to increase or decrease production quantity according to inventory.

Provided that the product inventory at the factory is $S_{i}$, remaining product of manufacturing is $B_{i}$, product inventory at agencies is $R_{i}$ and the remaining product-of distribution is $B_{k}$, the equation (8) is used to control the planned production volume $Q_{i}$ based on inventory level.

$$
Q_{i}(u)=P_{i}(u)-S_{i}-B_{i}-R_{i}-B_{k}
$$

\subsection{Materials Planning}

In the materials planning phase, the material requirements planning (MRP) is conducted. .Based on the production volume determined in the master production plan, the total requirements for various terms are decided from the bill of materials (BOM), and then the inventory on hand and remaining orders are subtracted to calculate the net total requirement by term. Subsequently, the ordering system (quantum ordering or regular ordering), safety 
inventory and purchase lot size are controlled to determine the purchase order volume. When making the actual order, it also becomes necessary to consider the procurement lead time for the parts. The purpose of the control here is to avoid having excess inventory and prevent opportunity loss from not having an inventory of spare parts.

The planning term is one day. The purchase lead time is taken in consideration to decide whether to make a purchase or to decide the purchase volume per day, based on the inventory of parts and the planned production volume. If the BOM is $G_{i j}$, the total requirements $G_{j}$ would be as described in equation (9).

$$
G_{j}(u)=Q_{i}(u) G_{i j}
$$

If the inventory of parts is $E_{j}$ and the remaining parts to be procured is $B_{j}$, the required amount of parts in a day $N_{j u}$, considering the current inventory of parts, is as defined by equation (10).

$$
N_{j u}(t)=\frac{G_{j u}(t)-B_{j}(t-1)-E_{j}(t-1)}{30}
$$

If the scheduled manufacturing amount in relation to the planned production volume is $U_{i u}$, the safety inventory coefficient is $\xi$ and the purchase lead time per part is $L T_{j}$, the setting of the purchase point $T_{j}$, which is the control target, can be realized by the equation (12).

$$
\begin{aligned}
I_{a} & =\frac{\sum_{n} \sum_{l} U_{l i u}(n) G_{i j}}{n} \xi \\
T_{j} & =\frac{\sum_{n} \sum_{l} U_{l i u}(n) G_{i j}}{n} L T_{j}+I_{a}
\end{aligned}
$$

The setting of purchase order volume $X_{j u}(t)$ is as described in equation (13).

$$
X_{j u}(t)=\left(L T_{j}+1\right) N_{j}(u)
$$

\subsection{Short-Term Planning}

In short-term planning, the scheduling that determines the production item for one day is performed. The production items obtained in the master production planning are allocated to manufacturing lines. In this study, the number of manufacturing lines is assumed to be two. The four types of product items are controlled to be allocated to two manufacturing lines to enable the manufacturing as scheduled.

In this model, down time is also considered and thus only one item is assumed to be produced on one line per day. In addition, manufacturing lead time is set as 1 to some days for each item and the production volume is set at maximum production capacity of each line.

Based on the planned production volume obtained from the rolling planning, lead time is also considered to decide which item to produce, the quantity to produce for each item, the line to be used for manufacturing and the 
order of manufacturing. The production volume for one production run of each item is assumed to be constant within one month. Furthermore, in order to make detailed production adjustments that conform to inventory, a weekly scheduling is performed based on the monthly planned production volume obtained from the rolling planning. For each week, production is increased or decreased in relation to the inventory.

Given that inventory is $S_{i}$ and the safety inventory is $I_{i}$, the weekly planned production volume $M_{i v u}$ can be defined by equations (14) and (15).

$$
\begin{aligned}
& \text { Beginning of the month: } \quad M_{i v u}(w)=\frac{Q_{i v}(u)}{4} \\
& 2^{\text {nd }} \text { to } 4^{\text {th }} \text { week of the month: } M_{i v u}(w)=M_{i v u}(w-1)-\left(S_{i}-I_{i}\right)
\end{aligned}
$$

The production volume per production for a product item $\varepsilon i$ would be as described in equation (16) if the manufacturing lead time of a product item is $L T_{i}$ and the maximum production capacity of a manufacturing line is $C$.

$$
\varepsilon_{i}=\min \left[\frac{\left(L T_{i}+1\right) M_{i v u}(w)}{60}, C\right]
$$

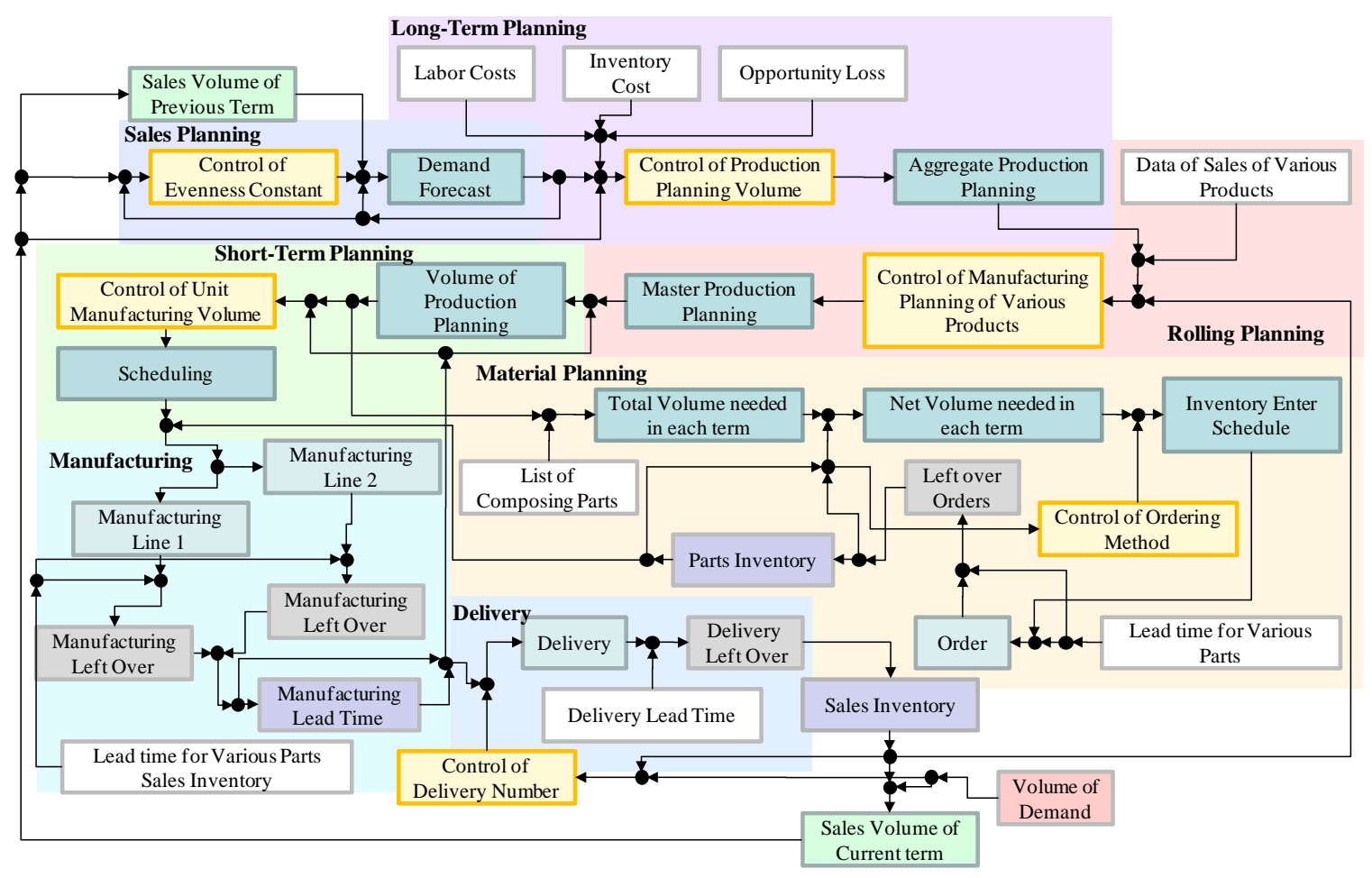

Figure 4: Diagram of Causal Relationship in the Whole Model 
Figure 4 shows the causal relationship, taking into consideration the above-mentioned control items. The nodes are represented with the following colors: orange for control, blue for plan, light blue for process (purchase ordering, manufacturing, distribution), purple for inventory, gray for remaining manufacturing, remaining purchases and remaining distribution, and white for the constants. Each control has an individual feedback loop. For some controls, the output is directly provided as feedback, and for other controls, the sales from the current term, which is the final output, is provided as feedback. Figure 5 is a mathematical model of Figure 4.

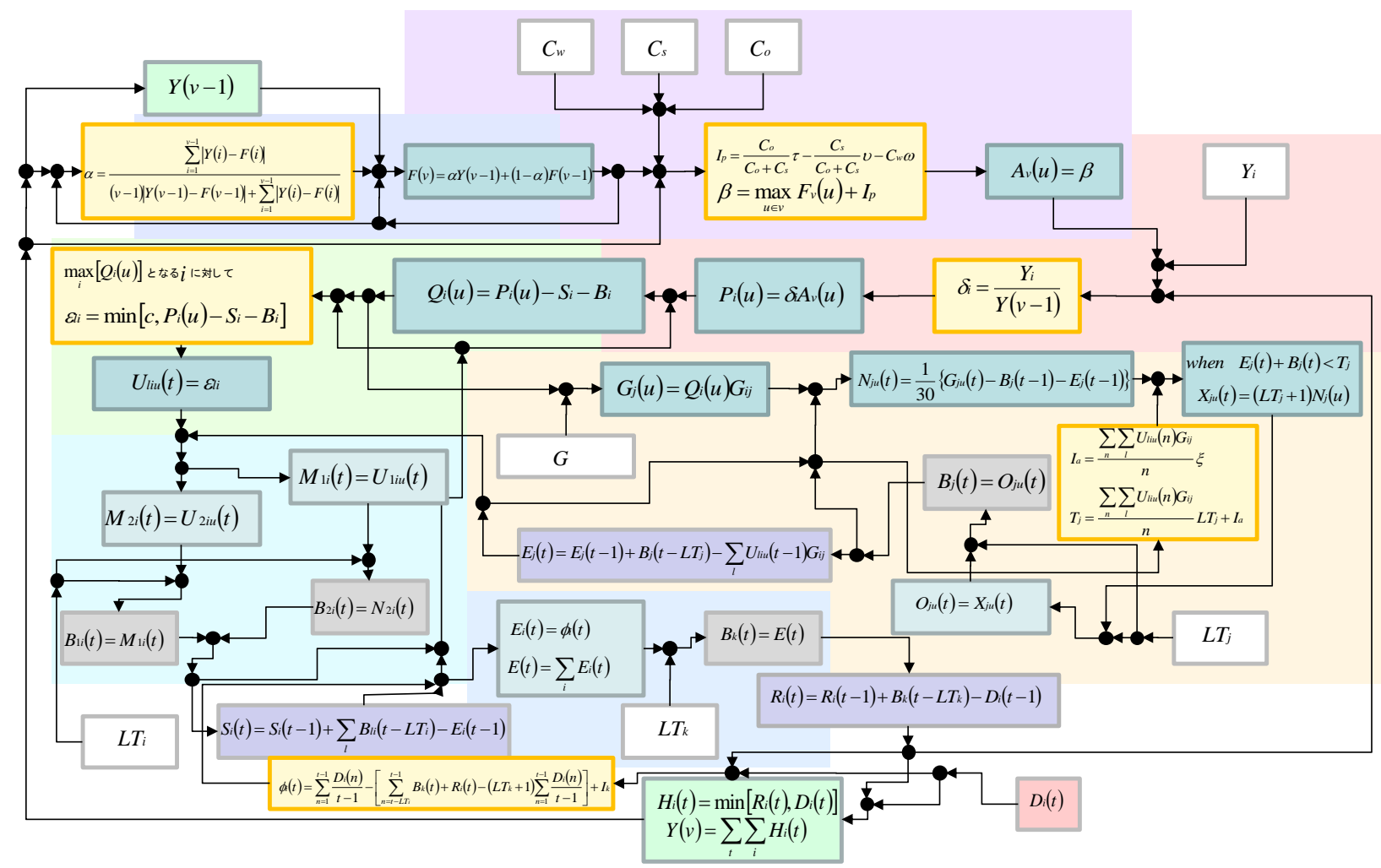

Figure 5: Mathematical Model of the Whole Model

\section{SIMULATION}

\subsection{Simulation}

The mathematical model illustrated in Figure 5 is made into a program using the formula manipulation software "Maple." The controls and processes at each node are defined as one procedure (proc()) and are chained together to produce a process for one term. The sales volume from the current term, which is the final output, is used as the demand forecast input for the following term and looped to the processes of the following term.

The results of the simulation for the product inventory at agencies (sales inventory), product inventory at the factory (product inventory) and the inventory of parts at the factory (parts inventory), which are represented by purple nodes in Figure 4, are as shown in Figure 6. 

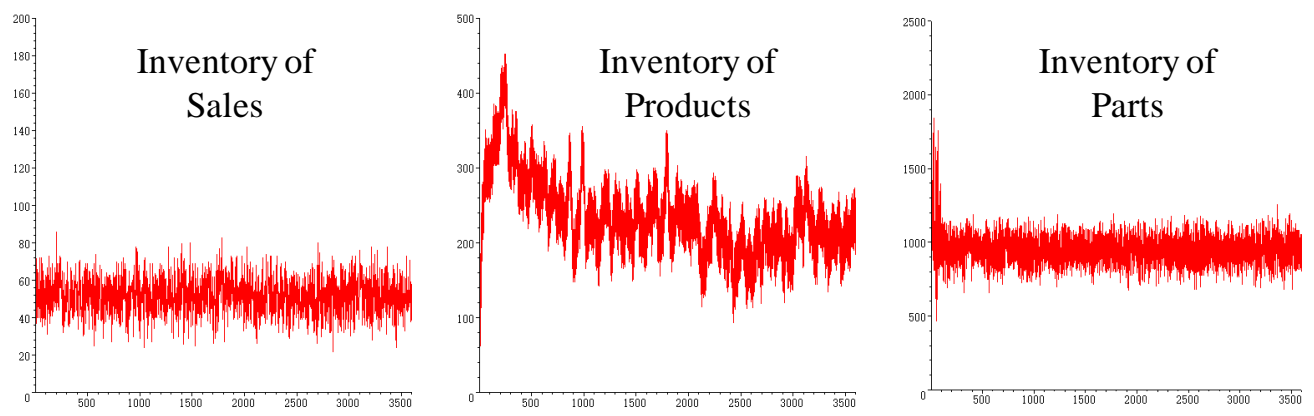

Figure 6: Transition of Inventory

These simulation results are defined as the basic model that has the utmost accuracy. Then, in order to find the impact of the factors required for decision-making items, the factors are neutralized. Specifically, the variables of the factors are replaced as constants. Alternatively, it can be omitted from the model to remove the impact of that factor. As a result of simulating after omitting the factor, the accuracy is considered to deteriorate compared with the result of the basic model (fluctuation of inventory increases). Consequently, the factor with greater accuracy deterioration can be understood as the factor with a higher degree of impact.

Next, the degree of impact of the factor is evaluated from increase rate of results derived from comparing the average and the standard deviation of inventory with those of the basic model. The comparative rate for each factor is given in Table 1.

This procedure was performed on all factors. Table 2, 3 and 4 show the results of investigating the factors that have an increase rate (hereafter referred to as "impact rate") within $+5 \%,+7 \%$ or $+10 \%$ in regard to the average value and standard deviation of inventory.

Table 1: Example of Results

\begin{tabular}{|c|c|c|c|}
\hline & $\begin{array}{c}\text { Product Inventory } \\
\text { in Sale Shops }\end{array}$ & $\begin{array}{c}\text { Product Inventory } \\
\text { in Factory }\end{array}$ & $\begin{array}{c}\text { Parts Inventory } \\
\text { in Factory }\end{array}$ \\
\hline Average & 51.59 & 220.99 & 958.76 \\
(Compared to Basic Model) & $(99.58 \%)$ & $(91.45 \%)$ & $(99.56 \%)$ \\
\hline Standard Deviation & 9.17 & 57.97 & 104.80 \\
(Compared to Basic Model) & $(99.13 \%)$ & $(95.78 \%)$ & $(100.43 \%)$ \\
\hline
\end{tabular}

Table 2: $\quad$ Factors that have an Impact Rate of $+5 \%$ or Less

\begin{tabular}{|c|c|c|}
\hline \multirow{2}{*}{ Control } & \multicolumn{2}{|c|}{ Increase Rate } \\
\hline & Above $5 \%$ & $5 \%$ Or less \\
\hline Control of Evenness Constant & $\begin{array}{c}\text { Recent sales } \\
\text { Changes in past sales }\end{array}$ & \\
\hline Control of Manufacturing Planning & Volume Inventory Cost & $\begin{array}{c}\text { Labor Costs } \\
\text { Cost of Opportunity Loss }\end{array}$ \\
\hline $\begin{array}{c}\text { Control of Manufacturing Planning } \\
\text { of Various Products }\end{array}$ & $\begin{array}{l}\text { Changes in past sales of } \\
\text { Various Products } \\
\text { Manufactured Inventory } \\
\text { of Various Products } \\
\text { Current Inventory of } \\
\text { Various Products }\end{array}$ & \\
\hline Control of Ordering Method & $\begin{array}{c}\text { Ordering Method } \\
\text { Lot Size } \\
\text { Safety Inventory }\end{array}$ & \\
\hline $\begin{array}{l}\text { Control of Unit } \\
\text { Manufacturing Volume }\end{array}$ & $\begin{array}{c}\text { Unifying of Daily } \\
\text { Manufacturing Volume } \\
\text { Sequence of } \\
\text { Manufacturing } \\
\text { of Various Products }\end{array}$ & \\
\hline Control of Delivery Volume & $\begin{array}{c}\text { Left over of Delivery } \\
\text { Safety Inventory } \\
\text { Current Inventory }\end{array}$ & \\
\hline
\end{tabular}


Table 3: Factors that have an Impact Rate of $+7 \%$ or Less

\begin{tabular}{|c|c|c|}
\hline \multirow{2}{*}{ Control } & \multicolumn{2}{|c|}{ Increase Rate } \\
\hline & Above $7 \%$ & $7 \%$ Or less \\
\hline Control of Evenness Constant & $\begin{array}{c}\text { Recent sales } \\
\text { Changes in past sales }\end{array}$ & \\
\hline Control of Manufacturing Planning & Volume Inventory Cost & $\begin{array}{c}\text { Labor Costs } \\
\text { Cost of Opportunity Loss }\end{array}$ \\
\hline $\begin{array}{c}\text { Control of Manufacturing Planning } \\
\text { of Various Products }\end{array}$ & $\begin{array}{c}\text { Manufactured Inventory } \\
\text { of Various Products } \\
\text { Current Inventory of } \\
\text { Various Products }\end{array}$ & $\begin{array}{c}\text { Changes in past sales of } \\
\text { Various Products }\end{array}$ \\
\hline Control of Ordering Method & $\begin{array}{c}\text { Lot Size } \\
\text { Safety Inventory }\end{array}$ & Ordering Method \\
\hline $\begin{array}{c}\text { Control of Unit } \\
\text { Manufacturing Volume }\end{array}$ & $\begin{array}{c}\text { Unifying of Daily } \\
\text { Manufacturing Volume } \\
\text { Sequence of } \\
\text { Manufacturing } \\
\text { of Various Products } \\
\end{array}$ & \\
\hline Control of Delivery Volume & $\begin{array}{c}\text { Left over of Delivery } \\
\text { Safety Inventory } \\
\text { Current Inventory }\end{array}$ & \\
\hline
\end{tabular}

Table 4: Factors that have an Impact Rate of $+\mathbf{1 0 \%}$ or Less

\begin{tabular}{|c|c|c|}
\hline \multirow{2}{*}{ Control } & \multicolumn{2}{|c|}{ Increase Rate } \\
\hline & Above $10 \%$ & $10 \%$ Or less \\
\hline Control of Evenness Constant & Recent sales & Changes in past sales \\
\hline Control of Manufacturing Planning & Volume Inventory Cost & $\begin{array}{c}\text { Labor Costs } \\
\text { Cost of Opportunity Loss }\end{array}$ \\
\hline $\begin{array}{c}\text { Control of Manufacturing } \\
\text { Planning } \\
\text { of Various Products }\end{array}$ & $\begin{array}{c}\text { Current Inventory of } \\
\text { Various Products }\end{array}$ & $\begin{array}{l}\text { Changes in past sales of } \\
\text { Various Products } \\
\text { Manufactured Inventory } \\
\text { of Various Products }\end{array}$ \\
\hline Control of Ordering Method & $\begin{array}{c}\text { Lot Size } \\
\text { Safety Inventory }\end{array}$ & Ordering Method \\
\hline $\begin{array}{c}\text { Control of Unit } \\
\text { Manufacturing Volume }\end{array}$ & $\begin{array}{c}\text { Unifying of Daily } \\
\text { Manufacturing Volume } \\
\text { Sequence of } \\
\text { Manufacturing } \\
\text { of Various Products }\end{array}$ & \\
\hline Control of Delivery Volume & $\begin{array}{c}\text { Left over of Delivery } \\
\text { Safety Inventory } \\
\text { Current Inventory }\end{array}$ & \\
\hline
\end{tabular}

\subsection{Discussion on the Impact Rate}

When the impact rate is $+5 \%$ or lower, the results demonstrated that almost all factors need to be taken into consideration. When the impact rate is $+10 \%$ or lower, there are upstream factors that do not require consideration, but for the planning close to the downstream process of production, most factors need to be 
considered. The results for the impact rate of $+7 \%$ or lower revealed an intermediate aspect between what was observed in the $+5 \%$ and $+10 \%$ or lower cases. These results demonstrated the importance of lower-stream planning in the whole flow of planning, from sales planning to distribution planning. In particular, scheduling and distribution are directly linked with inventory, which is the evaluation index, and require high accuracy. Upper-stream planning showed low necessity of decision-making consideration than lower-stream planning. The reason for this is thought to be the possibility of adjustment in the lower-stream planning when upper-stream planning shows certain roughness against demand. But this is not to say that there is no necessity for decision-making consideration in the upper-stream planning, but rather, simulation results showed planning beyond adjustment in down-stream will cause unignorable change in inventory volume.

\section{CONCLUSION AND PROSPECTS}

This study reviewed the elements that must be considered in the decision-making in each planning phase by modeling the flow of the supply chain from the sale planning to distribution. As a result, it was discovered that elements in the planning closer to production have greater impact. In the modern-day manufacturing industry, information exchange founded on the supply chain is well spoken of, but the production activities that actually produce profits are more important. It is essential to improve competitive edge by realizing production equipment and technologies as well as appropriate planning focused on the production activities.

Furthermore, the model in this study was designed to enable the expanded consideration of real-life situations at production sites. However, what is actually carried out at production sites is not only routine work, but also the enhancement of production capacity through capital investment and kaizen activities of employees. By adding these elements to the model in this study, consideration of decision-making can go beyond the limit of a simple chain of planning phases, and production with higher accuracy than those used in this model may be achieved.

\section{AUTHOR INFORMATION}

Hiroki Inagaki is working for NTT Data Corporation. He obtained his Master's degree from Aoyama Gakuin University.

Dr. Daisuke Doyo is an Assistant Professor in the School of Science and Engineering at Aoyama Gakuin University, Japan. He obtained his Ph.D. degree from Keio University in 2008. His current study interests are in the Skill Transfer Management and Supply Chain Design.

\section{REFERENCES}

1. Doyo, D., Sakamoto, K., Aoki, K., “A Study of Production Transaction-related Model Using Control Theory" , Proceedings of the 12th International Conference on Human-Computer Interaction , 855-862, (2007)

2. Forrester, J. Industrial dynamics, a major breakthrough for decision makers. Harvard Business Review July-August pp, 67-96, (1958)

3. Forrester, J. Industrial dynamics. MIT Press, Cambridge, MA, USA, (1961)

4. Najafi H, Bennett J E.: Inventory-production optimization using optimal control theory techniques. Proc Annu Southeast Symp Syst Theory, Vol. 16, 12-15, (1984)

5. Ortega M, Lin L: Control theory applications to the production-inventory problem: a review. Int J Prod Res Vol.42, No.11, 2303-2322, (2004)

6. Schwaninger M, Vrhovec P: Supply system dynamics: distributed control in supply chains and networks. Cybern Syst, Vol.37, No.5, 375-415, (2006)

7. Wiendahl H-P. : Backlog-Oriented Automatic Production Control. CIRP Ann, Vol. 50, No.1, 331-334, (2001) 